\title{
A COMPARATIVE STUDY OF THE RELIABILITY OF THE POWER ELECTRONICS IN GRID CONNECTED SMALL WIND TURBINE SYSTEMS
}

\author{
Md. Arifujjaman, M. T. Iqbal, J. E. Quaicoe \\ Graduate Student, Associate Professor, Professor \\ Faculty of Engineering, Memorial University, St. John's, NL A1B 3X5
}

\begin{abstract}
This work presents a reliability analysis of the Power Conditioning System (PCS) for both the Permanent Magnet Generator (PMG) and Wound Rotor Induction Generator (WRIG)-based small wind turbine generation systems. The PCS for grid connection of the PMG-based system requires a rectifier, boost converter and a grid-tie inverter, while the WRIG-based system employs a rectifier, a chopper and an external resistor in the rotor side with the stator directly connected to the grid. Reliability of the PCS is analyzed for the worst case scenario of maximum conversion losses at a predetermined wind speed. The analysis reveals that the Mean Time Between Failures (MTBF) of the PCS of a WRIG-based small wind turbine is much higher than the MTBF of the PCS of a PMG-based small wind turbine. The investigation is extended to identify the least reliable component within the PCS for both systems. It is shown that the inverter has the dominant effect on the system reliability for the PMG-based system, while the rectifier is the least reliable for the WRIG-based system. This research indicates that the WRIG-based small wind turbine with a simple PCS is a much better option for small wind energy conversion system.
\end{abstract}

Index Terms - Wind turbine, permanent magnet generator, wound rotor induction generator, reliability

\section{INTRODUCTION}

A small scale Wind Energy Conversion System (WECS) has tremendous diversity of use and operating conditions, and consequently has evolved rapidly along with the large scale WECS for generation of electricity either on-grid or off-grid applications. Such a WECS is considered as a complex system of many subsystems ranging from mechanical (rotor, hub, gear box etc.) to electrical (converter/inverter, rectifier, control) systems and loads. Failures in any subsystems cause substantial financial loss owing to the cost of replacement and restoration. The problem becomes more severe for small systems since as small wind turbines are very subjective to installation costs and require a reliable operation over a long period of time. In view of present uses and future developments, there is significant need for reliability evaluation for the WECS in order to ensure a reliable operation and low initial cost.

Almost all commercially available Small Wind Turbines (SWTs) are based on Permanent Magnet Generators (PMGs). The Power Conditioning Systems (PCSs) for grid connection of the PMG-based system requires a rectifier, boost converter, and a grid-tie inverter (Fig. 1). On the other hand, a small wind turbine may be based on a Wound Rotor Induction Generators (WRIGs) for the generation of electricity. The WRIG-based system can employ a rectifier, a chopper, and an external resistor in the rotor side, while the stator is directly connected to the grid (Fig. 2). These two PCS options could have different Mean Time Between Failures (MTBF) due to the contribution of the same stress in diverse proportion on their power electronic components. This is because the reliability of the power electronic components is influenced by the component temperature and its variations [1]. Knowledge of the reliability of power electronic components is a key concern when differentiating between systems. Indeed, accurate reliability data of either rectifier, converter, or inverter is helpful to provide an indepth sense of the reliability of the PCS.

Recent research focuses on the reliability computation and advancement of the inverter rather than the PCS [1,2]. Most of the reliability estimations are based on the accessible data provided in the military handbook for reliability prediction of electronic equipment which is criticized for being obsolete and pessimistic [2]. Rohouma et al [3] provided a reliability calculation for an entire PV unit by considering the individual failure rates of each power electronics module; however, the calculation suffers by the valid justification that the data provided by the author is considered from the manufacturers' published data which is somewhat questionable. Although power electronic component reliability calculation is well described, there is a general lack of description for the entire power electronics of an on-grid or off-grid application in the wind turbine area. On the strength of the 


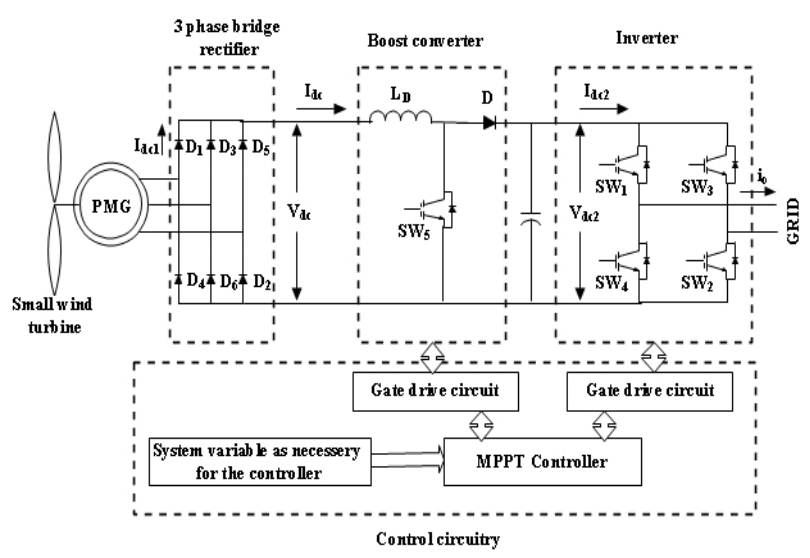

Fig. 1. A PMG-based small wind turbine

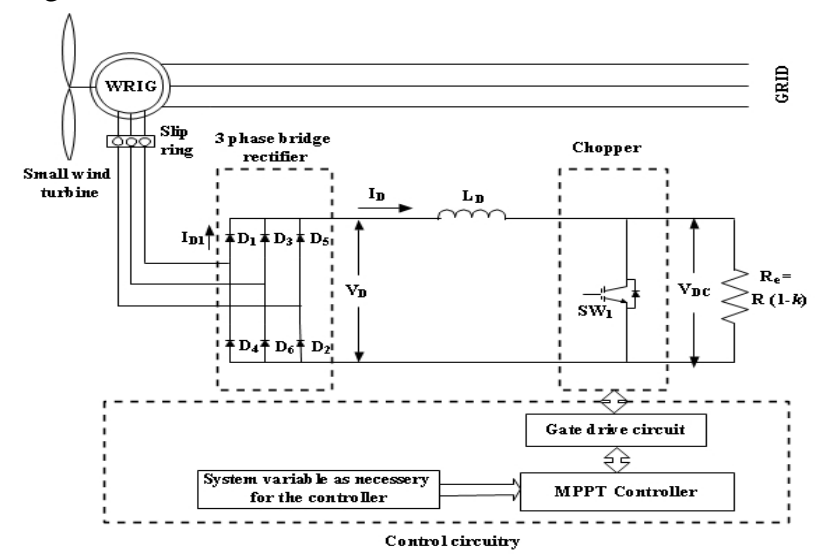

Fig. 2 A WRIG-based small wind turbine

above argument, this research aims to calculate the reliability of the PCS for a grid connected PMG and WRIGbased SWT system. Temperature is used as a stress factor which is a common practice during calculation of the power electronics components reliability [1]. The MTBF for both systems is presented and in addition, the least reliable component of the PMG and WRIG-based system is identified through quantitative analysis.

\section{RELIABILITY CALCULATION}

Reliability is the probability that a component will satisfactorily perform its intended function under given operating conditions. The average time of satisfactory operation of a system is the Mean Time Between Failures (MTBF) and a higher value of MTBF refers to a system of higher reliability and vice versa. As a result, engineers and designers always strive to achieve higher MTBF of the power electronic components for a reliable design of the power electronic systems. The MTBF calculated in this paper is carried out at the component level and is based on the life time relationship where the failure rate is constant over time in a bathtub curve. In addition, the system is considered repairable. It is assumed that the system components are connected in series from the reliability standpoint. The lifetime of a power semiconductor is calculated by considering junction temperature as a covariate for the expected reliability model. The junction temperature for a semiconductor device can be calculated as $T_{J}=T_{A}+P_{\text {loss }} R_{J A}$

where $R_{\mathrm{jA}}$ is the thermal resistance between the junction and ambient; $\mathrm{T}_{\mathrm{A}}$ and $\mathrm{T}_{\mathrm{J}}$ is the ambient and junction temperature respectively; $\mathrm{P}_{\text {loss }}$ is the power loss (switching and conduction loss) generated within a semiconductor device and can be found by replacing the $\mathrm{P}_{\text {loss }}$ from the loss calculation of both systems for each component. The life time, $\mathrm{L}\left(\mathrm{T}_{\mathrm{J}}\right)$ of a semiconductor is then described as

$L\left(T_{J}\right)=L_{0} \exp \left(\frac{B}{\Delta T_{J}}\right)$

where $\mathrm{L}_{0}$ is the quantitative normal life measurement (hours) assumed to be $1 \times 10^{6} ; \mathrm{B}=\left(\mathrm{E}_{\mathrm{A}} / \mathrm{K}\right), \mathrm{K}$ is Boltzman's constant which has a value of $8.6 \times 10^{-5} \mathrm{eV} / \mathrm{K}, \mathrm{E}_{\mathrm{A}}$ is the activation energy, which is assumed to be $0.2 \mathrm{eV}$, a typical value for semiconductors [4], $\Delta \mathrm{T}_{\mathrm{J}}$ is the variation of junction temperature and can be expressed as

$\frac{1}{\Delta T_{J}}=\frac{1}{T_{A}}-\frac{1}{T_{J}}$

The failure rate is described by [5]

$\lambda=\frac{1}{L\left(T_{J}\right)}$

The global failure rate, $\lambda_{\text {system }}$ is then obtained as the summation of the local failure rates, $\lambda_{\mathrm{i}}$ as:

$\lambda_{\text {system }}=\sum_{i=1}^{N} \lambda_{i}$

The Mean Time Between Failures, $\mathrm{MTBF}_{\text {system }}$ and reliability, $R_{\text {system }}$ of the system are given respectively by

$$
\begin{aligned}
& \operatorname{MTBF}_{\text {system }}=\frac{1}{\lambda_{\text {system }}} \\
& \mathrm{R}_{\text {system }}=e^{-\lambda_{\text {system }}}
\end{aligned}
$$

\subsection{Reliability Calculation for a PMG-based SWT}

The reliability analysis for the PCS of the PMG-based system is performed by the formulation described in section 2. A Matlab program is developed which computes the component junction temperature using the conduction and switching loss formulations developed in reference [6]. After the determination of the failure rate for each component using (4), the program sums up the failure rates to evaluate 
the total system failure rates (5). The reliability of the system is obtainable once the system MTBF (6) is known.

\subsection{Reliability Calculation for a WRIG-based SWT}

The procedure described in section 2 is used to calculate the reliability of the rectifier and chopper for the WRIG-based system. A partial stress prediction method is used to calculate the reliability of the external rotor resistor. The method calculates the failure rate of any component by multiplying a base failure rate with operational and environmental stress factors (electrical, thermal etc). It is assumed that the chopper carries a predetermined duty cycle variation. The power loss in the external resistor can be found by simply subtracting the power losses of the chopper from the total power loss produced by the rotor rectified voltage and current. Based on this computation, a commercially available resistor is selected and the stress ratio, $\alpha$ is calculated as the ratio of the operating power to the rated power of the resistor.

\section{RESULTS}

The analytical calculations illustrated in the preceding section were carried out to determine the MTBF and consequently the reliability of the systems for a predetermined wind speed condition. The rated power for the wind turbine is assumed to be $1.5 \mathrm{~kW}$. The expected operating condition of the wind turbine is $13 \mathrm{~m} / \mathrm{s}$. It is assumed that the generator speed is proportional to the output voltage of the 3-phase rectifier for the PMG-based system. A $15 \%$ slip variation is considered for the WRIGbased system for the reliability calculation. The analytical calculation is based on the data sheet on the EUPEC IGBT module FP15R12W1T4_B3 [7]. The results of the analysis following the procedure outlined are presented in Table 1 and Table 2 respectively.

Table 1 Component reliability for a grid connected small PMG-based system

\begin{tabular}{|c|c|c|c|}
\hline Quantity & Rectifier & Chopper & External resistor \\
\cline { 2 - 3 } & Diode & IGBT & 110.7862 \\
\hline $\begin{array}{c}\text { Power loss } \\
{[\mathbf{W}]}\end{array}$ & 9.0582 & 36.8386 & --- \\
\hline $\begin{array}{c}\text { Junction } \\
\text { temperature } \\
{\left[{ }^{0} \mathbf{K}\right]}\end{array}$ & 311.1344 & 375.3610 & $1.3605 \times 10^{5}$ \\
\hline $\begin{array}{c}\text { Life } \\
\text { expectancy } \\
{[\mathbf{h r}]}\end{array}$ & $8.4841 \times 10^{5}$ & $4.4818 \times 10^{5}$ & $7.3500 \times 10^{-8}$ \\
\hline $\begin{array}{c}\text { Failure rate } \\
{\left[\mathbf{h r}^{-1}\right]}\end{array}$ & $1.1787 \times 10^{-6}$ & $2.23131 \times 10^{-6}$ & \\
\hline
\end{tabular}

Table 2 Component reliability for a grid connected small WRIG-based system

\begin{tabular}{|c|c|c|c|c|c|}
\hline \multirow{2}{*}{ Quantity } & Rectifier & \multicolumn{2}{|c|}{ Boost Converter } & \multicolumn{2}{|c|}{ Inverter } \\
\cline { 2 - 6 } & Diode & Diode & IGBT & Diode & IGBT \\
\hline $\begin{array}{c}\text { Power loss } \\
{[\mathbf{W}]}\end{array}$ & 1.4256 & 9.9536 & 52.8391 & 6.8440 & 6.8440 \\
\hline $\begin{array}{c}\text { Junction } \\
\text { temperature } \\
{\left[\mathbf{}^{0} \mathbf{K}\right]}\end{array}$ & 300.0671 & 312.4328 & 353.4810 & 316.4789 & 312.3725 \\
\hline $\begin{array}{c}\mathbf{L i f e} \\
\text { expectancy } \\
{[\mathbf{h r}]}\end{array}$ & $9.7353 \times 10^{5}$ & $8.3536 \times 10^{5}$ & $5.4270 \times 10^{5}$ & $7.9662 \times 10^{5}$ & $8.3596 \times 10^{5}$ \\
\hline $\begin{array}{c}\text { Failure rate } \\
{\left[\mathbf{h r}^{-1}\right]}\end{array}$ & $1.0272 \times 10^{-6}$ & $1.1971 \times 10^{-6}$ & $1.8426 \times 10^{-6}$ & $1.2553 \times 10^{-6}$ & $1.1962 \times 10^{-6}$ \\
\hline
\end{tabular}

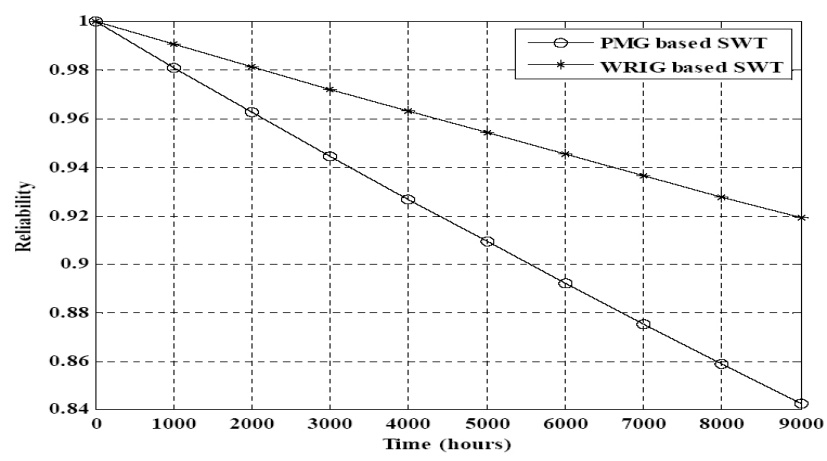

Fig. 3 Reliability of the power conditioning system during a year

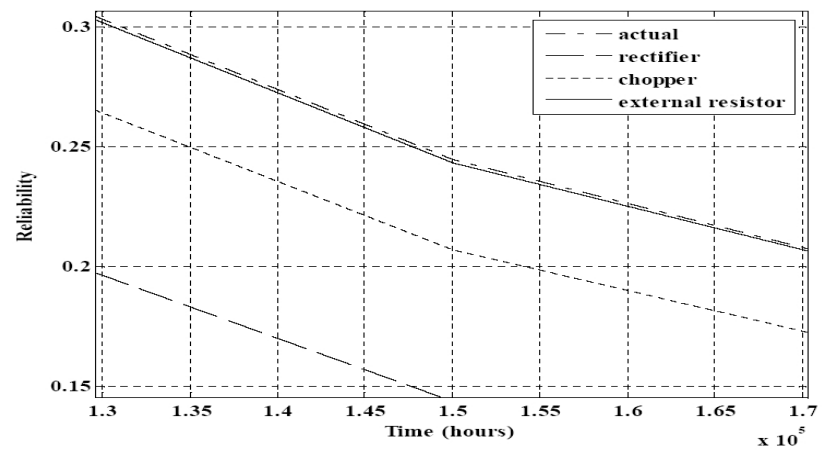

Fig. 4 Effect of reliability variation on the system reliability for the PMG-based system

The calculation reveals that the PCS failure rate for the PMG-based system is $1.9009 \times 10^{-5}$ and the MTBF is $5.2607 \times 10^{4}$ hours (6 years). The corresponding figures for the WRIG-based system are $9.3768 \times 10^{-6}$ and $1.0665 \times 10^{5}$ hours (12 years). It is well understood that the small wind turbine and the PCSs need to be affordable, reliable and most importantly, almost maintenance free for the average person to consider installing one. As can be seen, the need to replace the PCS for the PMG-based system corresponds to the MTBF value of 6 years. This leads to a more vulner- 


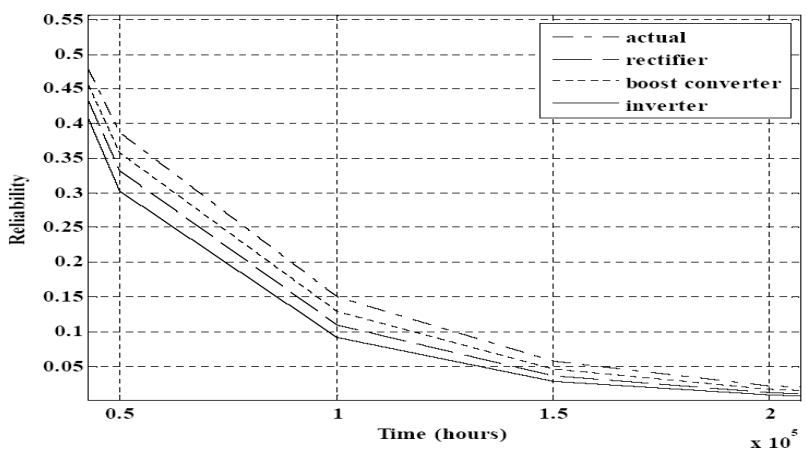

Fig. 5 Effect of reliability variation on the system reliability for the WRIG-based system

-rable system as compared to the lifespan of the wind turbine system, which is usually 15 to 20 years. Also from the financial standpoint, replacement of such a complex PCS is expansive and needs a highly skilled repair professional. In contrast to the PMG-based system, the WRIG-based system exhibits longer lifetime and remains in a good agreement with the lifespan of the wind turbine.

Fig. 3 shows the reliability of the PCS for a period of one year ( 8760 hours) for the PMG and WRIG-based system. The result reveals that the reliability of the PCS for the PMG-based system drops to $84 \%$ after one year, while the reliability of the PCS for the WRIG-based system drops to 92\% after one year. In this scenario, the PCS of the WRIGbased system illustrates higher reliability than the PMGbased system. The higher reliability value of the WRIGbased system is certainly advantageous in terms of maintenance and replacement costs.

Following the calculation of the reliability of the systems, an attempt is made to identify the subsystems in the PCS that are the least reliable. To achieve this objective for the PMGbased system, the MTBF of the rectifier is decreased by $50 \%$ while the MTBFs of the boost converter and inverter are unchanged. In the same way, the effect of changes in the MTBFs for each of the boost converter and inverter on the system reliability has been calculated and is presented in Fig. 4. It is observed that the inverter has the most dominant influence on the system reliability, while the boost converter has less significant effect than the rectifier. It has been found in the literature that the inverter is the least reliable subsystem [8]. This study confirms the results through quantitative analysis. In a similar manner, the effect of the rectifier, chopper and external resistor of the WRIG-based system is investigated with a reduction in MTBF of 50\% for each, and presented in Fig. 5. It has been found that the rectifier is the least reliable component in the PCS of such a system. From the financial standpoint, a rectifier is easily replaceable while replacement of an inverter is expensive and needs a highly skilled repair professional. The PCS of the WRIG-based system is composed of fewer parts as well as a lower failure rate. Maintenance and replacement costs of the WRIG-based system will be lower and thus favorable for the small wind turbine industry. As a whole, the scope of research should aim for a WRIG-based system that will have a lower failure rate as well as less complex architecture and consequently will be more reliable and less costly during operation.

\section{CONCLUSIONS}

The reliability analysis of the power conditioning system for a grid connected PMG and WRIG-based SWT system is presented. Temperature is used as a stress factor for the reliability analysis and it is found that the PCS of the PMGbased system suffers from low reliability as compared to the WRIG-based system. The least reliable component of the PCS is identified as the inverter and rectifier for the PMG and WRIG-based system respectively. It is shown that the WRIG-based system with a simple PCS could be an optimum alternative for future research in the small wind turbine system area.

\section{Acknowledgements}

The authors would like to thank the National Science and Engineering Research Council (NSERC) Canada for providing financial support of this research.

\section{References}

[1] D. Hirschmann, D. Tissen, S. Schroder, and R.W. De Doncker "Reliability Prediction for Inverters in Hybrid Electrical Vehicles," IEEE Transactions on Power Electronics, 22(6), pp. 2511 - 2517, 2007

[2] A. L. Julian, and G.A. Oriti, "Comparison of Redundant Inverter Systems to Improve Voltage Source Inverter Reliability," IEEE Industry Applications Conference, Paris, France, pp. 16741678,2006

[3] W.M. Rohouma, I.M. Molokhia, and A.H. Esuri, "Comparative Study of Different PV Modules Configuration Reliability," The Ninth Arab International Conference on Solar Energy (AICSE-9), Kingdom of Bahrain, pp. 122-128, 2007

[4] www.siliconfareast.com

[5] J.D. Neely "Fault Types and Reliability Estimates in PMAC Machines," M.S. thesis, Michigan State University, 2005.

[6] Md. Arifujjaman, M.T. Iqbal, and J. E. Quaicoe "A Comprehensive Loss Calculation in Grid Connected Small Wind Turbine Systems," $18^{\text {th }}$ IEEE NECEC conference, St. Johns, NL, November 6, 2008.

[7] www.infineon.com

[8]R. Tirumala, P. Imbertson, N. Mohan, C. Henze, and R. Bonn "An Efficient, Low Cost DC-AC Inverter for Photovoltaic Systems with Increased Reliability," Proceedings of the Industrial Electronics Conference (IECON), Sevilla, Spain, pp. 1095-1100, 2002 